\title{
The Effectiveness of Teaching Techniques to Improve the Classroom Management Based on Adler-Dreikurs Approach on the Degree of the Self-efficacy and Psychological Well-being of Teachers
}

\author{
Sheida Islami
}

Graduate Master of Educational Psychology, Farhangian University, Iran.

\begin{tabular}{|c|c|}
\hline ARTICLE INFO & ABSTRACT \\
\hline $\begin{array}{l}\text { Keywords: } \\
\text { Improving Class } \\
\text { Management } \\
\text { Adler and Dreikurs } \\
\text { Self-Efficacy } \\
\text { Psychological } \\
\text { Well-Being } \\
\text { Teacher. }\end{array}$ & 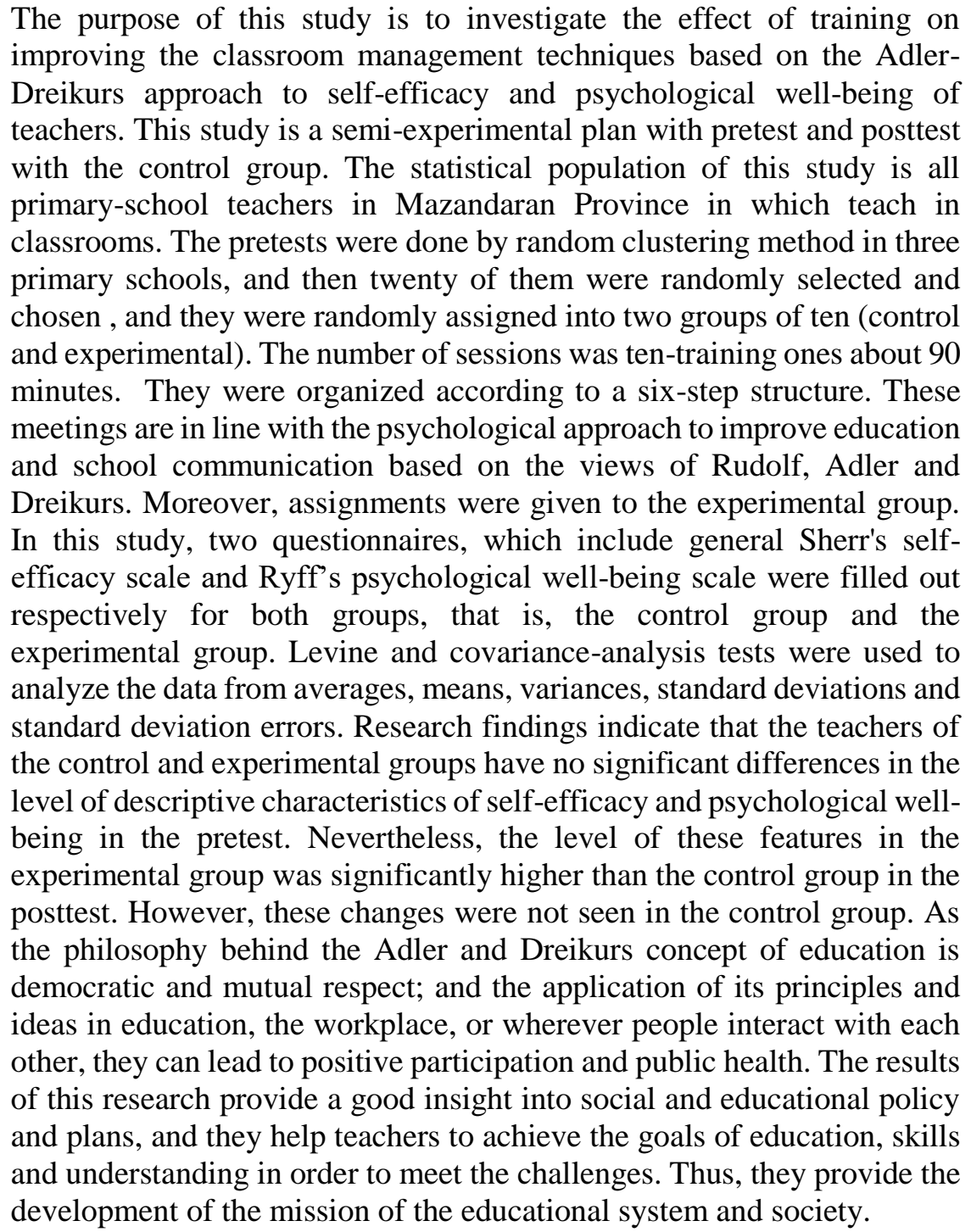 \\
\hline
\end{tabular}

\section{Introduction}

The classroom is the frontline of the education (Berliner, 1988), and the classroom management is the prerequisite for effective classroom education, and it is an important part of the education process (Germine, 2002). It is teacher's responsibility to manage and fulfill the educational and training goals (Dreikurs, 2004). According to Long \& Frey \& Vinstin Lang, the classroom

* Corresponding Author E-Mail Address: eslami_s@yahoo.com 
management, which is to create the best possible atmosphere for learning, is considered as the first priority of teacher's responsibilities in the classroom. In this case, he can provide the best atmosphere for learning (Quoted from Martin \& Shoho, 2003).

Moreover, Martin and Yin (2004) describe class management as an umbrella for classroom activities, and it creates the socio-psychological atmosphere of the class, and it has three aspects. The first one is the education management, the second one is the person management, and third one is the behavior management. The class management as an important indicator of teachers' work is a complex management that is named as "Art". We have repeatedly heard this concept in the familiar phrase "Teaching is an art". Therefore, a comprehensive classroom management system can create the organized classes in which learning is done optimally (Germine, 2002). Among the psychological theories, the Adler-Dreikurs psychological approach is the one known as a psycho-educational approach, and it is a present-future-oriented and short-term approach. This theory is hypothetically consistent, integrated, and it is somehow a combination. Furthermore, it can clearly integrate cognitive and systemic perceptions (Mosak \& Maniniacci, 1999). Its psychological features and assumptions are also consistent with the cultural values of many ethnic and racial groups. It has great potential for use in various cultural communities (Watts \& Pietrzak, 2000). Adler's therapist sees an individual as discouraged not as a patient. (Kanz, 2001). For this reason, Adler-orientated theorists do not seek to cure anything, but rather, they consider treatment as a kind of encouraging, reciprocal, and reassuring process. (Wats, 2008). It shows acceptance, and it rewards the collaborations, and besides it leads the person to assess his performance. This theory also induces faith and belief. (Carns et al., 1998). This is unique to each individual (Rathert \& Reed, 2001), and it is a particular attitude toward human nature (Evans, 2005). It not only is just one thing to be gained through other people (Carlson et al., 2007); but also involves focusing on all sources that can be converted to one or more points (A. Eckstein et al., 2000). Adler's psychology has been a set of special skills for 55 years (Evans, 2005) including encouragement and democratic relationships, the induction of faith and assurance of one's personality and abilities, listening and understanding, acknowledgment of action, being non-judgmental, being patient with others, focusing on efforts or progress, and being optimistic about positive visions. It makes them dare to describe the incompleteness, and it has been clarified by Dreikurs, Grunwald and Pepper, and nowadays this theory is more useful than it used to be in the past (Ali Zadeh and Sajjadi, 2010). The classroom as a social system is a set of interconnected roles. This as a whole coherent unit seeks to fulfill educational and training goals, and it is a place in which prepares people for life in a changing world. The realization of the educational and training goals in the classroom, like other social organizations, requires effective and efficient management. It is accomplished through plans such as programming, organizing, leading, motivating, controlling and evaluating. (Roger, 1999). Due to this principle that the classroom is also a social organization, the successful management of the class requires effective teacher performance. Considering the management activities, they try to reach the organizational goals, and this issue is the one that they try to make a suitable atmosphere for learning and thinking. (Zare, 2005). Techniques for improving and working in each profession have their own rules, and it can be true for teaching as well. We often misunderstand that teachers who love teaching are necessarily efficient teachers. However, the cases mentioned above are necessary for any qualified teacher, but they are not enough, because teaching is a skill which people must be taught. Teaching has a variety of complexities. This is accompanied by decency and effort. By the way, teaching is a sensitive management of human beings. Teaching is the simultaneous management of the brains (information, thoughts and beliefs). Teaching is the management of hands (skills), and hearts (feelings, emotions, tendencies and values). In other words, teaching is the management of learning, teaching and successes. (Shoarinjad, 2005). The importance and necessity of the study of the techniques of improving class management should be 
considered in order to identify teachers' management styles, and how they organize the classroom, and learning atmosphere. It is necessary to know teachers' skills in teaching, evaluating, identifying students' motivational models and the bases of doing homework. These techniques enable the teacher to effectively control the students in order to provide a positive learning atmosphere (Williams \& Sternberg, 2000). Self-efficacy and psychological well-being are motivational aspects, and each of them is positively related to well-being and happiness and mental health. Self-efficacy emphasizes cognitive components, and the psychological wellbeing emphasizes the emotional aspect. Accordingly, they are correlated positively (Davelaar et al., 2008). Since self-efficacy beliefs affect the amount of effort and persistence that we spend on work, the self-efficacy theory can weaken the self-efficacy beliefs of determinations and motivations, and they disrupt performance. Conversely, high self-efficacy beliefs facilitate participation in tasks, task selections, efforts and performances. (Klassen \& Lynch, 2007). Therefore, self-efficacy beliefs provide the basis for motivation and individual success. They ultimately provide human psychological well-being (Kurbanoglu, 2003). Regarding what was said about the effect of teachers' self-efficacy and psychological well-being on the positive effects of learning, the immediate benefit of this research is based on the most documented comments which are about the importance of class management and its role in learning, according to meta-analysis. Wang and his colleagues studied 179 valid articles in the field of learning. By making a conceptual framework, they categorized 228 effective learning variables into 30 categories within 6 groups. According to the results of the meta-analysis, the variable of interactive class management with an average of 2.07, after the meta-cognitive variable, has been proposed as the second most important and effective variable for learning (Wang, Herbert $\&$ Walberg, 1990). Therefore, teachers face challenges in classroom management. To solve these problems, teachers don't need to make students obey them; however, they need the students' collaborations and participations. The teachers' goal is to make students feel valuable in the classroom. By training on improving classroom management techniques based on Adler's theory, and the method developed by Dreikurs, one can create an atmosphere where different personalities in the classroom can learn subjects through the principles of democracy. As a result, it helps to improve the level of self-efficacy and psychological well-being of the teacher to teach much better, and they enjoy their work. As a result, students can change and become friendly people with experienced and organized learning. (Ali Zadeh and Sajjadi, 2010). The future benefit of research is that the results provide a good insight into social and educational policy and planning, and it helps teachers to get the skills they need to meet the challenges in the pursuit of excellence in education. Thus, it contributes to the development of the mission of the educational system and society. The overall aim of this study is to determine the effect of training on improving classroom management techniques based on the Adler-Dreikurs approach to self-efficacy and psychological well-being of teachers. The main hypotheses in this research are:

1- The training of improving classroom management techniques based on the Adler-Dreikurs approach influences teachers' self-efficacy.

2- Teaching improvement class management based on Adler-Dreikurs approach affects the psychological well-being of teachers.

\section{Research Method}

The research is a semi-experimental plan with pretest-posttest structure with control group. In this study, two groups of subjects are randomly selected; they are randomly assigned to two experimental and control groups. Then, before and after the independent variable, the subjects of the two groups were measured by pretest and posttest. The main purpose of this test is to infer the causal relationship between the phenomena being controlled (Hasanzadeh, 2004). 
The statistical population of this research includes all elementary teachers in Mazandaran province who are taught in the classroom. The pretests of research were done by random clustering method in three elementary schools. Then, 20 of them were randomly selected and randomly assigned to two groups of 10 (control and experimental). According to Shunaker and the training program builders, the number of experimental groups should be at least 4 people, and the maximum should be 10 people. (2001, Bahlman \& Dinter). The number of sessions is 10 training sessions about 90 minutes, and they are organized according to a specific 6-step structure. This is consistent with the content of the psychological approach for improvement of education and school communication based on Rudolf Dreikurs and Adler's views. In addition, assignments were given to the experimental group. To conduct this research, it initially requested the elementary school teachers of three schools to complete pretest studies; and then from among them, 20 teachers who were taught in different classes at the classroom were randomly selected. Next step, they were randomly assigned into two groups of 10 (control and experimental). Next, the experimental group was placed in classrooms, which consisted of 10 sessions of 90 minutes in group and workshop, and they were taught by the author under the training of classroom improvement techniques based on the Adler-Dreikurs approach. The 10 people. who were left out, did not receive any training programs. After the end of the sessions, both control and experimental groups completed the research tests.

\section{Educational Content}

The content of instruction is based on both classroom management techniques and democratic relationships with mutual respect which are consistent with the psychological approaches for the improvement of the school education and communication. This is based on the views of Rudolf Dreikurs, which was influenced by the individual psychology of Alfred Adler as an important contributor to the development of this theory and its methods. Ten-training sessions are organized based on a six-step structure. The first phase of a relaxation exercise is to give participants the opportunity to get rid of their daily concerns. During the practice of relaxation, the counselors give positive ideas and thoughts. Then, it discusses the feedback from the previous session assignments, in which the participant is given one minute to tell the rest of the group about his experience and about his assignment. Then, information about a specific topic is considered, in which the session focuses on it. The fourth step involves training related to this information. After the next week's homework is described, the session ends with another sedation exercise called the next step. During this tutorial, the counselor asks participants to think in ways that they can use the new skills and information of that meeting in their everyday lives, and he wants them to portray such situations. The titles and general content of 10 sessions are:

First session: Participants get acquainted with the general structure and rules of the training sessions with each other, and they discuss and learn about effective democratic methods.

Second session is teaching the concept of goal-oriented individual psychology and the psychological pattern of humans to participants.

Third session: Provides training in group dynamics and discussions related to the democratic class against the traditional class.

Fourth session: Educating the process of encouragement as the most fundamental dimension in motivating learners to learn.

Fifth session: Focuses on the cultural meanings of rewards and punishment.

Sixth session: This session introduces educational problems and learning disabilities.

Seventh session: Understanding ways to deal with some particular behavioral problems.

Eighth session: Explaining and extending the seventh session.

Ninth session: How parent-teacher discussions and sessions go on.

Tenth session: Finally, an evaluation of the previous sessions takes place. 


\section{Research Tools}

In this research, two questionnaires were used as research tools.

\section{A. The Sherr General Self-Efficacy Scale (SGSES)}

Some scholars have considered this concept as a general concept, and they called it public selfefficacy (Mersami, 2007). Self-efficacy theory is a model of cognitive processes for compromise. Sherr \& Maddux first developed a scale to measure this general belief called the Self-Efficacy Scale, which does not devote to a particular position of behavior. His reasons for making this scale are the first to provide a tool for further study on self-efficacy. Secondly, it is used in treating patients. They believe that treatment cycles have different effects on patients with different levels of self-efficacy. A general self-efficacy is a set of different experiences in failings and achievements that people transfer to a new position (Sherr and Maddox, 1982).

The Cronbach Alpha reliability coefficient, which Sherr et al. reported for the sub-scale of selfefficacy, is $86 \%$. (Hirschy \& Morris., 2002). Also, the alpha coefficient was $88 \%$ in the study by Kim and Amiz (2005). In his research, Ali Niae Karoee (2007) gained Cronbach's alpha equaled with 78\%, and it is acceptable. Similarly, Asghar Nejad et al. (2006) reported the Cronbach alpha of this scale equaled with $83 \%$. The validity of this scale was also verified in the review of the scale of general self-efficacy of Sherr et al. In other studies, there was no criterion for concurrent narrative (Kim and Amiz, 2005). In this study, the scores of the selfefficacy scale were correlated with internal control source scales, interpersonal competencies, self-esteem, self-esteem, daring, male characteristics and emotional adaptability. (Hirschy and Maurice, 2002). Asgharnejad et al. (2006) used factor analysis method (correlation $40 \%$ and higher) and criterion validity (at 0001/0). Both of them reported a high degree of validity.

\section{B. Ryff's Psychological Well-being Scale (RSPWB). Ryff's Scales of Psychological Well Being}

In the last decade, the tendency to examine the positive aspects of health has increased.

This test was designed by Ryff in 1980. In the past decade, Ryff and Keys proposed a model of psychological well-being, widely researched by the researchers. Psychological well-being is a multi-component concept and includes the following:

Self-acceptance: Positive attitude toward yourself and accepting different aspects of yourself, such as good and bad attributes and positive feelings about past life.

Positive relationships with others: the feeling of satisfaction and intimacy from the relationship with others and the importance of these attachments.

Autonomy: The feeling of independence and influence on life events and active role in behaviors.

Domination of the atmosphere: sense of atmospheric mastery, control of external activities and the effective use of peripheral opportunities.

Targeted life: having a goal in life and believing that his current and past lives are meaningful. Individual growth: The feeling of continuous growth and the acquisition of new experiences as a potential candidate (Akin, 2008).

In order to standardize the psychological well-being, Ryff performed this test on 321 people, and he reported the coherence coefficient under the scale of this questionnaire as follows:

Autonomy is $(76 \%)$, atmospheric domination is $(90 \%)$, individual growth is $(87 \%)$, positive relationship with others is (91\%), purposeful life is (90\%) and self-acceptance is (93\%).

The reliability of the sub-scale re-testing method was also found in a test of 117 cases in the 6week interval between $81 \%$ and $85 \%$. In another study, the internal consistency coefficient of the sub-scales of autonomy is (87\%), atmospheric mastery is (77\%), individual growth is (74\%), positive relationship with others is $(83 \%)$, targeted life is $(76 \%)$, and self-admission is 
(79\%). The reliability of the sub-scales re-testing method is between $74 \%$ and $84 \%$ at an 8 week interval. The correlation of psychological well-being scales with a number of tools to assess welfare is indicative of the validity of this questionnaire as follows:

The correlation with the emotional balance scale is $(25 \%)$, the individual development scale is $(62 \%)$, the atmospheric mastery scale, the correlation with the life satisfaction scale is (28\%), and the self-esteem scale of the self-acceptance scale is (73\%). The correlation with Rosenberg self-Esteem scale is between (29\%) and (62\%) of the individual growth scale.

The correlation with the scale of depression of Zhong is $(60 \%)$, the degree of mastery of the atmosphere of $(33 \%)$ the purposeful life and with the other four measures are positively correlated (Edwards, 2007). Shokri et al. (2007) reported the Cronbach's alpha coefficients for the subscales of this test between $60 \%$ and $78 \%$. This instrument was first translated and standardized by Zanjani Tabasi (2004) in Iran. In this research, Cronbach's alpha is a total of $94 \%$ for its sub-scales it has been reported between $92 \%$ and $90 \%$. Content validity, structure, convergence and divergence of this tool have also been reported to be desirable.

In order to standardize the psychological well-being in Iran, an experiment with 145 students from Islamic Azad University in Azadshahr City was implemented. The reliability coefficient was $82 \%$ based on the retest reliability coefficient with Ryff psychological well-being scale.

Self-acceptance subscales, positive relationships with others, autonomy, atmosphere domination, purposeful life and personal growth were $71 \%, 77 \%, 78 \%, 70 \%, 77 \%, 78 \%$ respectively. They were statistically significant. In order to validate the construct of this test, the correlation between its scales and its overall correlation was evaluated, and the results indicate the validity of the psychological well-being scales (quoted by Baiani et al., 2008).

\section{Data Analysis Method}

To test the hypotheses of this study, we used mean, average, variance, standard deviation and standard error of members in pretest and posttest; and the Levine test was used both to create a condition for equality of variances and a test of covariance analysis and to analyze the data.

\section{Findings}

Table (1) shows the pretest and posttest data of self-efficacy scale of the control and experimental group.

Table 1: the pretest and posttest data of self-efficacy

\begin{tabular}{|c|c|c|c|c|c|c|c|c|c|c|c|c|}
\hline \multicolumn{3}{|c|}{ Variable } & 1 & 2 & 3 & 4 & 5 & 6 & 7 & 8 & 9 & 10 \\
\hline \multirow[t]{2}{*}{ control group } & Pretest & \multirow{4}{*}{ 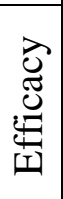 } & 48 & 54 & 43 & 64 & 51 & 42 & 63 & 69 & 68 & 57 \\
\hline & Post -test & & 48 & 56 & 44 & 66 & 53 & 42 & 63 & 69 & 69 & 59 \\
\hline \multirow{2}{*}{ Experimental group } & Pretest & & 48 & 53 & 43 & 51 & 64 & 71 & 42 & 78 & 76 & 59 \\
\hline & Post -test & & 54 & 58 & 52 & 65 & 76 & 78 & 59 & 81 & 81 & 72 \\
\hline
\end{tabular}




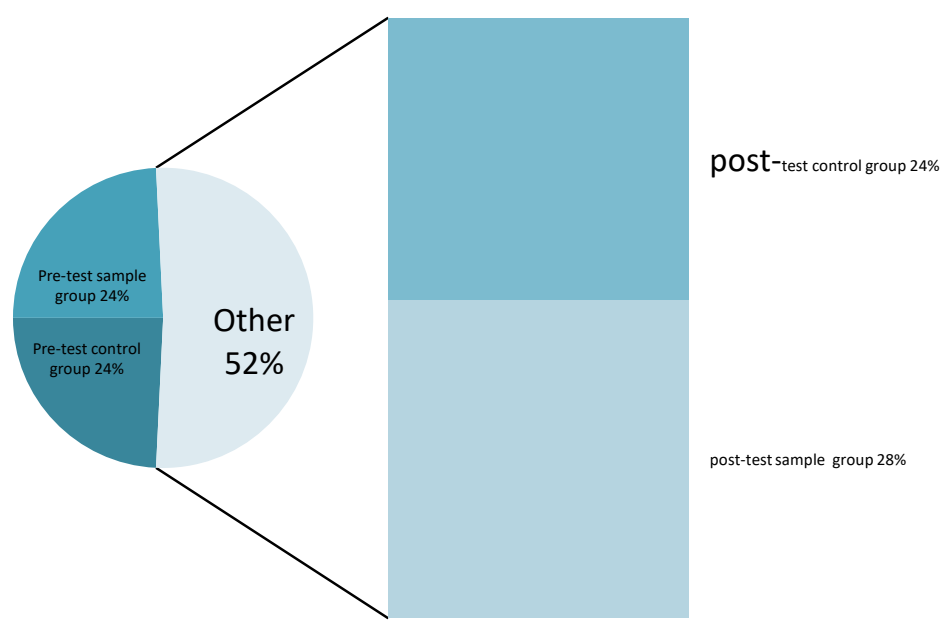

Chart 1: percentage of pretest and posttest data of the self-efficacy scale

Chart (1) shows the percentage of pretest and posttest data of the self-efficacy scale of the control and experimental groups.

Table (2) shows the pretest and posttest data of psychological well-being scale in the control and experimental group.

Table 2: The pretest and posttest data of psychological well-being scale

\begin{tabular}{|c|c|c|c|c|c|c|c|c|c|c|c|c|}
\hline \multicolumn{3}{|l|}{ Variables } & 1 & 2 & 3 & 4 & 5 & 6 & 7 & 8 & 9 & 10 \\
\hline \multirow{2}{*}{$\begin{array}{l}\text { Control } \\
\text { Group }\end{array}$} & Pretest & \multirow{4}{*}{ 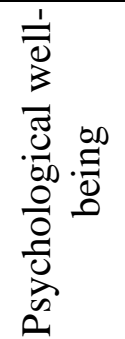 } & 403 & 352 & 363 & 372 & 378 & 398 & 412 & 402 & 400 & 398 \\
\hline & Posttest & & 408 & 362 & 373 & 372 & 382 & 398 & 422 & 420 & 420 & 423 \\
\hline \multirow{2}{*}{$\begin{array}{l}\text { Experiment } \\
\text { al group }\end{array}$} & Pretest & & 402 & 368 & 373 & 382 & 428 & 412 & 420 & 408 & 392 & 432 \\
\hline & Posttest & & 430 & 468 & 438 & 483 & 472 & 461 & 483 & 492 & 484 & 473 \\
\hline
\end{tabular}

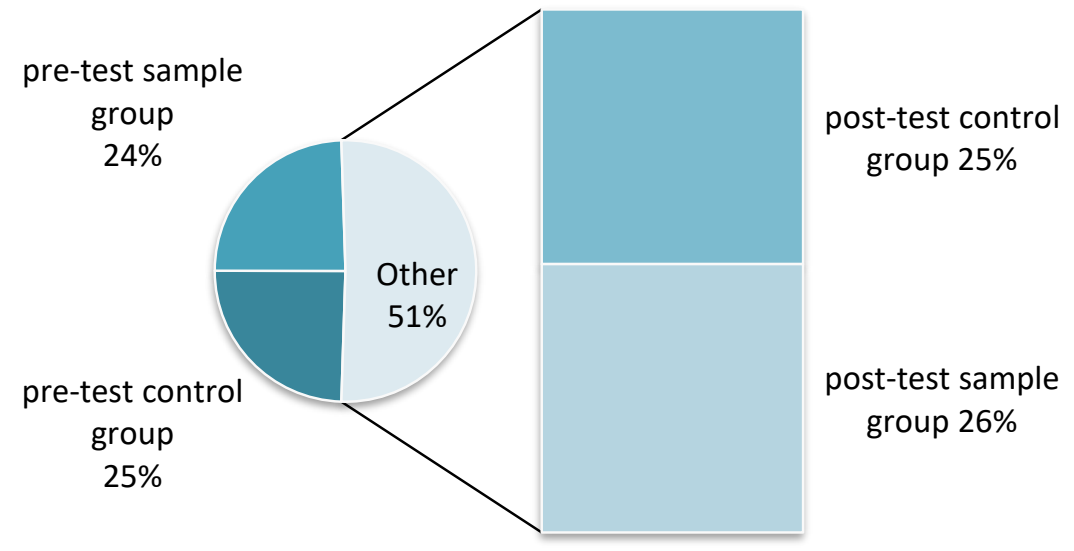

Chart 2: pretest and posttest data of the psychological well-being scale 
Chart (2) shows the pretest and posttest data of the psychological well-being scale of the control and experimental group

Table (3) shows the descriptive statistics of the control and experiment group on the selfefficacy scale.

Table 3: the descriptive statistics of the control and experiment group on the self-efficacy scale

\begin{tabular}{|c|c|c|c|c|c|c|c|}
\hline \multicolumn{2}{|l|}{ Variables } & Tests & Average & Mean & Variance & $\begin{array}{c}\text { The standard } \\
\text { deviation }\end{array}$ & $\begin{array}{c}\text { Standard } \\
\text { deviation error }\end{array}$ \\
\hline \multirow{3}{*}{ Control group } & \multirow{6}{*}{ 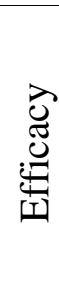 } & Posttest & 59.50 & 57.50 & $36 / 27$ & 6.02 & 1.90 \\
\hline & & Pretest & 59.20 & 57.50 & 49.73 & 7.05 & 2.23 \\
\hline & & Differences & 0.30 & 0 & 13.46 & 1.03 & 0.33 \\
\hline \multirow{3}{*}{$\begin{array}{l}\text { Experimental } \\
\text { group }\end{array}$} & & Posttest & 59.70 & 56 & 104.45 & 10.22 & 3.23 \\
\hline & & Pretest & 69.10 & 68.50 & 91.43 & 9.56 & 3.02 \\
\hline & & Differences & 9.40 & 12.50 & 13.02 & 66.0 & 0.21 \\
\hline
\end{tabular}

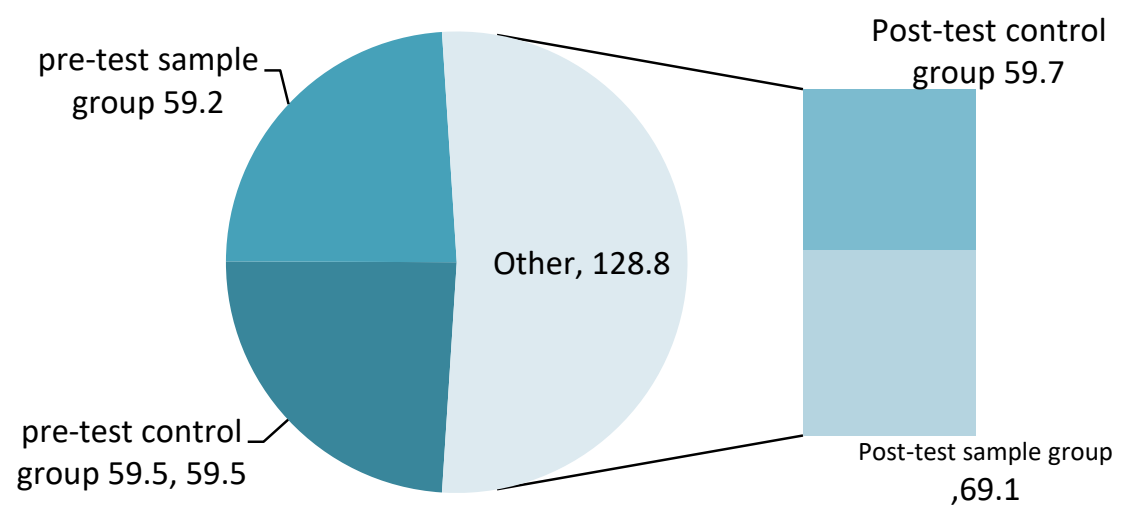

Chart 3: the comparison of control and experimental group in self-efficacy scale

The table and diagram (3) contain descriptive characteristics of self-efficacy in the control and experimental group including average, mean, variance, standard deviation and standard deviation error of members in pretest and posttest, and then they were compared and their differences were analyzed. The data from this table show that there is no significant difference between the level of descriptive characteristics of self-efficacy in the control and experimental groups in the pretest. Unlike the control group, the post-test of descriptive characteristics of self-efficacy of the experimental group has risen.

Table 4: descriptive statistics of the control and experimental group on the scale of psychological well-being

\begin{tabular}{|c|c|c|c|c|c|c|c|}
\hline \multicolumn{2}{|l|}{ Variables } & Tests & Average & Mean & Variance & $\begin{array}{l}\text { Standard } \\
\text { Deviation }\end{array}$ & $\begin{array}{c}\text { Standard } \\
\text { Deviation Error }\end{array}$ \\
\hline \multirow{3}{*}{$\begin{array}{l}\text { Control } \\
\text { Group }\end{array}$} & \multirow{6}{*}{ 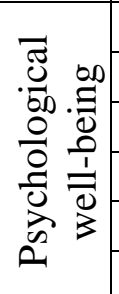 } & Posttest & $387 / 80$ & 398 & 401.95 & 20.04 & 6.34 \\
\hline & & Pretest & 398 & 403 & 569.11 & 23.85 & 7.54 \\
\hline & & Differences & 10.20 & 5 & 164.16 & 3.81 & 1.2 \\
\hline \multirow{3}{*}{$\begin{array}{l}\text { Experimental } \\
\text { group }\end{array}$} & & Posttest & 401.70 & 405 & 503.56 & 22.44 & 7.09 \\
\hline & & Pretest & 468.40 & 47.502 & 412.71 & 20.31 & 6.42 \\
\hline & & Differences & 66.70 & 67.50 & 90.85 & 2.13 & 0.67 \\
\hline
\end{tabular}




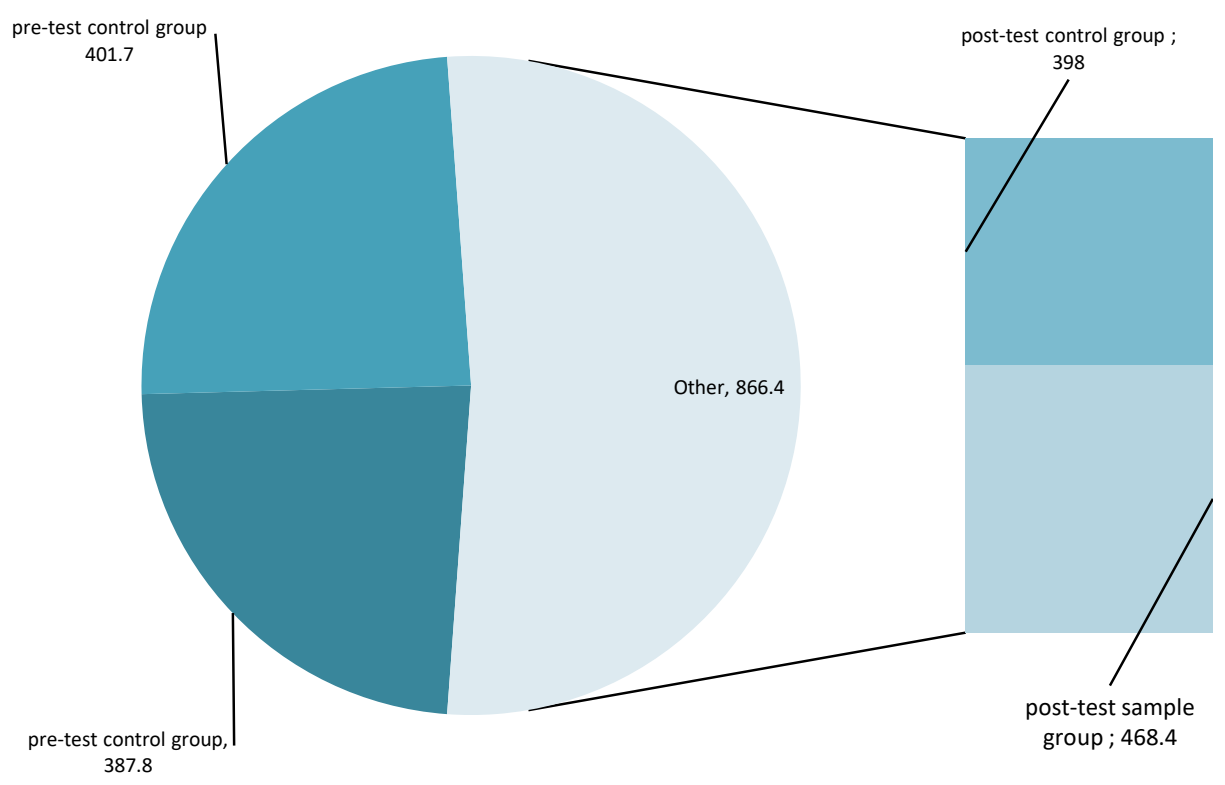

Chart (4) comparison of control and experimental groups in the psychological well-being scale

The table and chart (4) contain descriptive features of psychological well-being in the control and experimental group, including average, mean, variance, standard deviation and standard deviation error of members in pretest and posttest, and then they were compare and their differences have been investigated. The data of this table show that the descriptive features of psychological well-being of the control and experimental group in the pretest were not significantly different. But in the posttest, the descriptive characteristics of the psychological well-being of the experimental group have increased in comparison with the control group.

Table 5: Data analysis using Levine test.

\begin{tabular}{|l|c|c|c|c|}
\hline Exams & F & DF1 & DF2 & sig \\
\hline Efficacy & 2.24 & 1 & 18 & 0.15 \\
\hline Psychological well-being & 4.33 & 1 & 18 & 0.052 \\
\hline
\end{tabular}

Findings of Table 5 show that the condition of equality of variances is established based on Levine's test to use the covariance analysis test for both self-efficacy variables and psychological well-being. That's because both variables indicate a significant level greater than levels of 0.05 and 0.01 .

Table (6) Effect of classroom management improvement training based on the Adler- Dreikurs approach on teachers' self-efficacy

\begin{tabular}{|l|c|c|c|c|c|}
\hline Sources Change & SS & DF & MS & F & P \\
\hline Pretest self-efficacy & 1017.61 & 1 & 1017.61 & 68.40 & 0.000 \\
\hline Independent variable effect group & 472.38 & 1 & 472.38 & 31.75 & 0.000 \\
\hline Error & 252.88 & 17 & 14.87 & - & - \\
\hline
\end{tabular}

Table (6) indicates that there is a significant difference between the self-efficacy scores of both the experimental and control groups in the posttest assuming that the pretest score is added as a companion variable at the confidence level of 99 . In other words, it can be said that the selfefficacy of the experimental group has improved on the self-efficacy of the control group in 
the posttest. It suggests that classroom management training based on Adler-Dreikurs approach was effective on the level of self-efficacy of the experimental group, and it improved their selfefficacy, as a result, the first hypothesis of this study confirms that the improvement of classroom management based on the Adler-Dreikurs approach affects teachers' self-efficacy.

Table 7: Difference between the scores of psychological well-being between the two experimental and control groups

\begin{tabular}{|l|c|c|c|c|c|}
\hline \multicolumn{1}{|c|}{ Sources Change } & SS & DF & MS & F & P \\
\hline Pre-test self-efficacy & 3134.46 & 1 & 3134.46 & 9.34 & 0.007 \\
\hline Independent variable effect group & 17061.21 & 1 & 17061.21 & 50.86 & 0.000 \\
\hline Error & 5701.93 & 17 & 335.40 & - & - \\
\hline
\end{tabular}

Table (7) indicates that there is a significant difference between the scores of psychological well-being between the two experimental and control groups in the posttest assuming that the pretest score is added as a companion variable at the confidence level of 99. In other words, it can be said that the psychological well-being of the experimental group is improved in comparison with the psychological well-being of the control group in the posttest. This suggests that classroom management education based on the Adler-Dreikurs approach has been effective on the psychological well-being of the experimental group, and their psychological well-being could promote them. As a result, the second hypothesis of this research confirms that the improvement of classroom management based on Adler-Dreikurs approach could affect teachers' psychological well-being.

\section{Discussion and Conclusion}

The purpose of this study was to determine the effectiveness of teaching the improvement techniques of classroom management based on the Adler-Dreikurs on self-efficacy and Psychological well-being of teachers. The findings from the interpretation of the results of this study, which were carried out through using covariance analysis, could confirm that there was a significant difference between the self-efficacy scores of the experimental and control groups in the posttest assuming that the pretest score was combined as a companion variable at a confidence level of $99 \%$. In other words, it can be said that the self-efficacy of the experimental group has improved on the self-efficacy in comparison with the control group in the posttest. It suggests that the training of improving classroom management techniques based on the Adler-Dreikurs approach was effective on the level of self-efficacy of the experimental group, and it improves their self-efficacy. As a result, the first hypothesis of this study is confirmed that the training of improving classroom management based on the

Adler-Dreikurs approach has an impact on the self-efficacy of teachers. Analysis of the data about the second hypothesis shows that there is a significant difference between the scores of psychological well-being between two groups, that is, the experimental group and control one in the posttest assuming that the pretest score is added as a companion variable at a confidence level of $99 \%$. In other words, it can be said that the psychological well-being of the experimental group is improved in comparison with the psychological well-being of the control group in the posttest. It suggests that the improvement of classroom management based on the Adler-Dreikurs approach has been effective on the psychological well-being of the experimental group. It could also promote their psychological well-being. As a result, the second hypothesis of this research confirms that the improvement of classroom management based on the Adler-Dreikurs approach affects teachers' psychological well-being. In general, the findings of this study coincide with the findings of the following studies, Oy et al., (2011), Josephson et al. (2011), Salami (2010), Moyira and Oliver (2008), Schroedefger et al. (2008), Martin (2008), Sneer et al. (2008), Islami and Valipour (2011), Ahdi et al. (2009), Ganji and 
Farahani (2009) and Naderi et al. (2009). In explaining these findings, it is deduced that the present research is based on a meta-analysis is consistent with the most documented views on the importance of class management and its role in learning. Wang and his colleagues conducted on 179 valid study articles. By designing a conceptual framework, they categorized 228 effective learning variables into 30 categories within 6 groups. According to the results of the meta-analysis, the variable of interactive class management has been proposed with a mean of 2.7 after the metacognitive variable as the second most important and effective variable on learning. (Wang, Herberg and Waalberg, 1990). Also, since the teacher self-efficacy and psychological well-being structures affect the positive outcomes of learning, teachers are faced with challenges in classroom management. To eliminate the, teachers do not need to subjugate students. Instead, they need the students' cooperation and participation, and the ultimate goal is to make students feel valuable. Teaching classroom techniques based on the Adler-Dreikurs approach can create an atmosphere for students with different characters to have class interactions with each other. As a result, it helps teachers to improve the level of self-esteem and psychological well-being, and they enjoy teaching, and students become friendly-minded citizens with experience and organized education. Its results provide a good insight into social and educational policy and planning, and it helps teachers get the skills and understanding that they need to deal with challenges in line with the high education goals. It can provide the development of the educational and social system.

\section{Research Suggestions}

- To investigate the effectiveness of the teaching of improving classroom management techniques based on Adler-Dreikurs approach on other variables such as depression, test anxiety, parent / child relationship, fear, the academic achievement and other personality characteristics of teachers and students of research should be done.

- Due to the fact that parents play an important role in parent-child relationship and parentteacher relations, parents must learn the democratic relationships and mutual respect. Then self-efficacy and psychological well-being of teachers are evaluated.

- further researches, in order to more accurately assess the effectiveness of the training of improving classroom management techniques based on the Adler-Dreikurs approach, in addition to general self-efficacy, the professional and social self-efficacy should be used, and furthermore the effectiveness of this training on each aspect of self-efficacy needs to be evaluated.

- Improving the management of classroom management based on the Adler-Dreikurs approach can progress the psychological well-being of teachers.

- By strengthening the self-efficacy beliefs, it is possible to increase the level of psychological well-being of individuals. Strengthening self-efficacy along with improving psychological well-being can be effective in improving educational quality.

- Managers and teachers in a longitudinal study should pay more attention to the more precise identification of classroom management styles at different levels of the curriculum, so that they can obtain more effective methods for teaching and improving classroom management.

- The philosophy behind the concept of training democratic relationships with the mutual respect and the application of its principles and ideas has led to positive participation and public health.

The principles such as education, relationships, work atmosphere, or wherever people are interacting, this method of education should be provided during in-service teacher training, counseling and family education; in addition, this should also be taught to students. 


\section{References}

Ahmadi, Batul; Narimani, Mohammad; Abul Ghasemi, Abbas; and Asians, Maryam. (2009). Investigating the relationship between emotional intelligence, document style and selfefficacy with life satisfaction of the employed women. Educational and Psychological Studies of Ferdowsi University. Volume 10, Issue 1.

Ali Asghar, Kashcheki Ashoor, Mohammad; and Bani, Ali. (2008). Validity and Reliability of the Ryff's Psychological Well-being Scale. Iranian Journal of Psychiatry and Clinical Psychology. Year 14, No. 2, Summer, 151-146.

Ali Nia Karavi, Rostam (2003). The Relationship between General Self-Efficacy and Mental Health of Students. Master's Thesis, Allameh Tabatabaei University, Tehran.

Ali Zadeh, Hamid; and Sajjadi, Habiba al-Sadat. (2010). Dreikurs, Rudolf, mutual respect in democratic relations. Tehran: Dangeh Publishing.

Asgharnejad, Tahereh, Ahmadi, Dehghatbaldini, Mohammad; Farzad, Vahllah; and Khadda Panahi, Mohammad Karimim. (2006). Study of psychometric properties of Sherr's selfefficacy scale. Journal of Psychology 10 (3): 274-262.

at:http://upetd.up.ac.za/thesis/available/etd-08112008-1222715/unrestricted/oofrent.pdf

Avey, J.B., Wernsing,T.S., \& Mhatre, K.H. (2011).A longitudinal Analysis of positive psychological constracts and emotions on stress, anxiety, and well-bing. Journal of leadership and organization studies.

Berliner, D.C. (1988). The development of expertisein pedagogy.New York: Longman.

Carlson, C., Clemmer. F., Jennings, T.,Thompson, C., \& Page, L. J. (2007). Organizational Development 101: Lessons from Star Wars, the Journal of Individual Psychology, 63, 425439.

Carns, M., \& Carns, W. (1998). A Review of the Profession Literature concerning the Consistency of the Definition and Application of Adlerian Encouragement, the Journal of Individual Psychology, 54, 72-89.

Davelaar,. P.M, Araajof, s., \& Kipper, D.A. (2008). The Revised Spontaneity Assessment Inventory (SAI-R): Relationship to goal orientation, motivation, perceived self-efficacy, and self-esteem, the Arts in Psychotherapy.35:117-128.

Dreikurs Rudolf and colleagues. (2009). Classroom management techniques (translators Hamid Alizadeh and Ali Reza Rouhahi). Tehran: Publishing House of Danesh (published in 1977).

Dreikurs, R. Cassel, P., \& Dreikurs ferguson, E. (2004). Discipline without tears. John wiley and Sons Inc.

Edwards, D.J. (2007). Sport psychological skills training and Psychological well-being in youth athletes. University of Pretoria.A vailable

EsKstein,D., Belongia, M., \& Elliott-Applegate,G. (2000). The Four Directions of Encouragement Within Families, the Family Journal: Counseling and Therapy for couples and Families 8(4):406-415.

Evans,T. (2005).The Tools of encouragement, The International child and Youth care Network 73. 
Ganji, Masoomeh; and Farahani, Mohammad Taghi. (2009). Relationship between job stress and self-efficacy with life satisfaction in Isfahan's gas disaster relief workers. Quarterly Journal of Psychological Health. Second Volume, 24 -15.

Germine,Yousset. (2002). An Investigation into the Influences of teachers classroom management Beliefs and practices on classroom procedures.

Hassanzadeh, Ramadan. (2004). Statistical Methods in Behavioral Sciences. Tehran: Saavallan Publishing.

Hirschy,A.J., \& Morris ,J.R. (2002).Individual Differences in Attributeional Style:The Relation Influence of Self-Efficacy,Self-Esteem and Sex RoleIdentitiy-Personality and Individual Differences,32,183-196.

Islamiand Valid Pour. (2011). Effectiveness of classroom management techniques based on the document of the fundamental transformation of education. Published in the Journal of the Teacher's conference in the knowledge-driven age.

Josefsson, K., \& et., al. (2011). Associations of personality profiles with various aspect of wellbeing, Epub ahead of print.

Kim,B.S.K,. \& omizo,M.M,. (2005).Asian and European American Cultural Values,Corective Self-Estem,Acculturative Stress,Cognitive Flexibility, and General Self-Efficacy Among Asian American Colege Students ,Journal of Counseling Psychology 52(3):412-41.

Klassen, R. M. \& Lynch, S.L. (2007). Efficancy From the Perspective of Adolescents with LD and their Specialist Teachers, Journal of learning disabilities, 40(6) : 494- 507.

Kurbanoglu, S. S. (2003). Self- efficacy: a concept closely literacy and lifelong learning, Journal of Documentation, 59 (6): 635-346.

Martin,N.K., \& shoho,A. (2003). Attitudes and Beliefs Regarding class management styles: The Impact of Teacher pre paration VS.Exprience.Research in the schools,10(2),29-34.

Martin,N.K., \& Zening yin. (2004). Construct Validation of the Attitude and Beliefs on classroom management control inventory. Journal of classroom Interaction. 33(2): 6-15.

Milkolajczak, M., \& Luminet, O. (2008). Trait emotional intelligence and the cognitive appraisal of stressful events: An exploratory study, personality and individual differences, Volume 44, Issue 7, 1445-1453.

Mirjamy, Marzieh; and Ebrahimi Ghavam, Soghri. (2007). The study of the relationship between self-efficacy, social support and test anxiety with the health of male and female students. Allameh Tabatabaei University. Quarterly Journal of Psychology and Educational Sciences, 2 (7): 91-73.

Mosak, H., \& Manianiacci, M, P. (1999). A Primer of Adlerian Psychology: The AnalyticBehavioral- Cognitive Psychology of Alfred Adler, Philadelphia: PA 9106.

Nadery et al. (2009). Flexibility relationship with self-efficacy and job satisfaction among employees. Research project of Islamic Azad University of Ahvaz.

Salami, S.O. (2010). Emotional intelligence, self- efficacy, psychological well-being and student's attitudes implications for quality education, European Journal of Educational Studies,2(3).

Sharinejad, Ali Akbar. (2005). Teacher training. Educational Teacher, Educational Technology Development Monthly. No. 179. 
Sherr, M., \& maddux,J.E.(1982).The self-efficacy seals: construction and validation. Psychological report,51. 663-671.

Shokri, omid, and colleagues. (2007), individual differences in identity and psychological wellbeing. New Developments in Cognitive Science. 9, No. 2, 46-33.

Wang, M.C.walberg,H.J., \& Herbert,G,D.(1990).What Influences learning? Journal Educational Research,84(1).

Wattes, R., \& Pietrzak, D. (2000). Adler Ian Encouragement and the Therapeutic Process of Solution Brief Therapy, Journal of counseling and Development, 78: 442-447.

Watts, R. (2003). Adler Ian Therapy as a Relational Constructivist Approach, the Family Journal: counseling and Therapy for Couples and families, II (2): 139-147.

Williams\&Stenberg. (2000).classroom Management.<http://muslting gom seul $\sim$ data base/organization.html./>

Wragg. E. C. (1999). An introduction to classroom observation. Second edition, New tork. Routlege falmer.

Zazar, Hussein. (2005). Classroom Management Teachers, Barriers and Strategies, Teachers' Meeting in the Knowledge-Driven Age. University of Esfahan. 